\title{
‘THINKING MAKES IT SO': REFLECTIONS ON THE ETHICS OF DISPLAYING EGYPTIAN MUMMIES
}

\author{
JASMINE DAY \\ The Ancient Egypt Society of Western Australia, Perth, Australia
}

\begin{abstract}
Controversy about museums' possession and exhibition of human remains has usually affected those identified as ancestral remains by indigenous peoples. Egyptian mummies, with their long tradition of exhibition, seemed exempt from such considerations until the covering of unwrapped remains in the Egyptian gallery at The Manchester Museum in 2008. The museum's representatives argued that this covering responded to visitors' objections, but subsequent widespread protest against the measure suggested that it had been carried out with inadequate public consultation. With reference to the Manchester case, I will present two arguments to expand the scope of current debates about human remains display. The first argument favours the consideration of museum visitors from cultures other than those represented by exhibited remains as legitimate stakeholders in the remains management, including consideration of their personal reasons and historical precedents for favouring display. The second argument, which reveals the spurious bases of many objections to Egyptian mummies' display and demonstrates their derivation from misconceptions promulgated by the media, shows that the grounds for public objections to human remains display should be more critically examined. If perpetuated rather than halted, the display of mummies could be used to actively combat disparaging media stereotypes. Human remains exhibition is not inherently offensive, but can be regarded as such by visitors whose cultural backgrounds fail to prepare them for encounters with the dead. Removing the dead from display avoids engagement with ethics debates rather than facing the challenge of finding ways to respect the dead by facilitating encounters with them.
\end{abstract}

Keywords: Egyptian, mummies, museums, exhibition, ethics 


\section{INTRODUCTION}

Mummy! thou shalt henceforth be to me as a companion. I will bear thee about with me in my wanderings, and learn lessons from the sad spectacle thou dost present.

Nicholas Michell, The Mummy of Thebes, 1860 (23: 190)

The sight of two mummy heads knocked onto the floor of a Cairo Museum research laboratory by vandals during Egypt's 25th January Revolution in 2011 reminded me of the worst excesses of tomb robbery and despoliation that bedevilled Egypt in the past. Widespread looting has now returned in the wake of political instability. This revival of an old and wretched practice also reminds me that even those Egyptian mummies safely deposited in museums abroad are increasingly becoming victims of another kind of beating in the game of political football. Objections to exhibiting ancient human remains in museums that originated among the repatriation claims of indigenous groups have lately been anticipated and expanded by well-intentioned curators to include even hitherto uncontroversial remains (20). I sensed some years ago that it would only be a matter of time before Egyptian mummies were declared unfit to be seen by the very public that loves them. Thus I was not surprised to hear in 2008 that the Manchester University Museum had entirely covered its fully and partially unwrapped mummies. What did surprise me was that the museum had taken this step without first extensively canvassing visitors' views about mummy displays - hoping instead to elicit these views by undertaking the cover-up (25) and had completely failed to anticipate the angry backlash that resulted (26).

I suspect that this ire reflected not only the disappointment of visitors denied an opportunity to see real ancient Egyptians, but also an outrage that the values of a majority of visitors, those other than indigenous peoples and pagans, were apparently not deemed worthy of consideration. Is this because the majority appear to be in conditional favour of the exhibition of Egyptian mummies (11: 129-68) and human bones (14) and threaten to derail the mission of the Sensitive New Age Curator to humanise mummies by hiding them? Considering that the large corpus of mummy-themed fiction and poetry penned in the nineteenth century, which strove to represent mummies as people instead of objects $(10,11,12)$, was inspired by commonplace experiences of seeing, touching and even unwrapping mummies, it seems ridiculous to assume that preventing visual and even tactile encounters with these bodies is the only means to humanise them. It may, in fact, have the opposite effect; it is to be noted that the rise of the mummy-as-monster in Hollywood cinema coincided with the period 
in which mummies were finally and literally withdrawn from public hands and placed behind glass, leaving visitors to ponder and ultimately fear what they must smell and feel like, and get up to at night (11: 106-13).

I want to expand the narrow scope of current debates about human remains display. Firstly, I will argue for the consideration of museum visitors from cultures other than those represented by exhibited remains as legitimate stakeholders in the remains' management, including consideration of their personal reasons and historical precedents for favouring display. Secondly, I want to show that the bases of many objections to Egyptian mummies' display are spurious and derive from misconceptions promulgated by the media, such that the grounds for public objections to their display should be examined more critically. If perpetuated rather than halted, the display of mummies could be used to actively combat disparaging media stereotypes.

\section{THE FORGOTTEN STAKEHOLDERS}

Listing the range of stakeholders consulted in conjunction with the 2008-9 exhibition of the Lindow Man bog mummy at the Manchester Museum, deputy director Piotr Bienkowski included 'museum staff, university staff, archaeologists, [a] councillor ... the community advisory panel, Pagans, and [the Pagan lobby group] Honouring the Ancient Dead: I hope I haven't missed anyone out' (20: 123) - but he had: museum-goers who are not affiliates or advisors of any of these groups, some of whom have a keen interest in archaeology or Egyptology, most of whom may not usually post their views on Manchester Museum's comments board or blog. These were the same people overlooked when the museum covered its Egyptian mummies. What this blind spot suggests is a view - perhaps held unconsciously - that if one is not indigenous, Pagan or actively involved in politics or legislation, one has no right to speak on the human remains issue.

Explaining its decision to cover its mummies, the Manchester Museum reported having received many complaints about its mummy display (27:1). How representative was this sample? Might the complaints be those of a vocal minority? Those satisfied with the display may not always have been moved to comment. Little systematic and large-scale research has been conducted into museum visitors' opinions about Egyptian mummy exhibits - even a new study of visitors to American mummy displays (35) does not investigate their ethical stances - so it is not advisable to interpret isolated objections to these exhibits as evidence of widespread offence. The most extensive study of visitor reactions to Egyptian mummies (11: 129-68), which was researched at a number 
of large and medium-sized museums in the United States, Britain and Australia in 1995-6, shows that the majority of visitors favour their exhibition, even if they place conditions upon it such as the removal of mummy fragments from display. This widespread approval is similar to that shown for the display of human bones in a 2009 British study (14), one of the principal findings of which is that generally speaking, the older the remains, the less objection their exhibit raises. Notwithstanding the different appearance of fleshed remains, which can disturb some viewers, the age of Egyptian mummies would likely offset many objections as it does for bones. A 2002 study of 300 visitors at several British museums found that $82.5 \%$ of respondents accepted mummies' display unconditionally (21).

Seeing mummies in museums is nothing short of a Western cultural tradition that engenders personal memories and meanings. It ought to be recognised as such and valued, not discarded in a hasty attempt to anticipate and appease a handful of critics. The experience of encountering mummies in our midst is a twentieth century legacy, a narrative fondly commemorated in thousands of children's books and cartoons that differs from the obsolete nineteenth century archetype of journeying far from home into a foreign land to see its ancient dead. The immediacy of mummy encounters that museums facilitate is cherished by people worldwide; it generates everything from a child's first awareness of death to an emotional connection with the ancient Egyptians, not to mention a more concrete understanding of Egyptian archaeology, history, religion and burial practices.

Certainly, one may question how much Egyptology may be learned simply by seeing a mummy; my museum visitor interviewees could seldom specify exactly what they had learned by looking. Yet their demeanours suggested some kind of enlightenment. I think that their encounters were more emotional than educative, but if modern curators (such as those of the Lindow Man exhibition) elsewhere accept the right of the visitor to make personal interpretations of exhibits, then this right should also apply here. Museums furnish not only educational experiences but also subjective ones, so the values of visitors who want to see mummies for personal reasons deserve recognition. Simple curiosity as a motivation for looking at mummies is no more or less subjective than Pagan reverence and may do as much to cultivate psychological development and personal well-being.

The removal of mummies from the visitor's gaze may create a sense that experts are reserving the right to look at mummies for themselves, denying this opportunity to laypeople. Popular culture has long critiqued this perceived 
exclusivity of experts; how often have scientist characters in films suffered the wrath of the dinosaurs or mummies they have revived? This horror film theme of the failure and folly of experts arguably vents a frustration that the general public, effectively locked out of museums and tombs, cannot participate in the practice of archaeology (15: 46). By contrast, characters like Indiana Jones and Lara Croft represent archaeologists as heroes because they invite audiences to vicariously participate in their exploits. Curators who propose to reduce public access to Egyptian mummies on the grounds that mummy exhibits are offensive are only repeating history:

The medical profession's labelling of [nineteenth century British] public anatomy museums as obscene can be seen as a strategy for creating a medical monopoly of anatomy by categorizing it as knowledge from which laypeople could be excluded on moral grounds. Under English obscenity laws, professionals, by virtue of their education, social background and character, were deemed impervious to influences that could corrupt the weaker-minded public.

A. W. Bates, "Indecent and Demoralising Representations", 2008 (4)

Are we to conclude that curators who cover or remove mummies believe that they alone are capable of rational moral judgment and that members of the general public are incapable of making sound ethical judgments about the things they see on display?

\section{THE FASHIONABLY OFFENDED}

Let those who from fastidiousness and delicacy shrink from attending the present exhibition bear in mind that excessive sensibility fosters ignorance ...

Anonymous, Senor Sarti's Celebrated Florentine Anatomical Venus, ca1847-54 (2)

In my experience, objections to displays of Egyptian mummies most often derive not from true empathy with the deceased, but from unconscious psychosocial concerns or from horror engendered by exposure to repulsive images of evil mummy characters in the mass media (11: 129-68; 35). Although this cultural milieu determines museum visitors' predispositions toward mummies it is seldom taken into consideration as the likely cause for many objections made to their display. The professionalisation of medicine, palliative care and 
the funeral industry has literally taken the dead out of our hands for nearly a century and as a consequence, widespread unfamiliarity with the visceral elements of death might produce extreme discomfort or sheer disbelief when museum visitors encounter mummies. Mummies are the first dead bodies that many people see and the majority of my interviewees visiting the Field Museum in Chicago did not believe that all of the bodies they had seen were authentic (11: 137). The shock of some visitors at seeing death may be equivalent to the Victorians' discomfort with sexuality and may account for some objections to mummies' display.

One kind of objection I have often seen written on museum comments boards is that the ancient dead should be reburied or should never have been disinterred. A common sentiment is that the writer would not like to be disinterred and would be repulsed to hear of his or her relative being dug up. Apart from demonstrating that many members of the public know nothing of the historical circumstances in which Egyptian mummies were removed from their tombs, nor of the issues that would be involved in reburying them locally or back in Egypt, such remarks raise the idea that the dead possess an inalienable right to remain buried forever, to own some plot of land in perpetuity. Certainly, mummies of any age and culture possess moral value (30), but how should this value be recognised? Bob Brier, a philosopher and mummy scientist, distinguishes between the rights of individuals that, he argues, expire with their deaths and the obligations of the living to honour the wishes of the deceased, insofar as these can be determined for ancient remains (8: 51). He accepts that while Egyptians did not wish to be disinterred, past circumstances that resulted in their disinterment cannot be undone and that any gestures we now make to express respect for mummies must be made in the context of the museum environment. Unlike the comments board objections, Brier's approach to mummy ethics is not ahistorical but accommodates historical contingencies. In an overpopulated world in which towns encroach upon cemeteries and ancient sites are threatened by construction works, ancient and historic cemeteries cannot always be left untouched. Room must be made for the living and the living, in turn, must learn to live alongside the displaced dead. The ancient Egyptian Harpist's Song concluded that tomb robbery made graves impermanent, so that we might as well forget about elaborate funerary preparations and carpe diem instead (31:145-6). Just as priests relocated the royal mummies to cache tombs for their protection in an era of widespread looting, ancient Egyptians might now recognise our relocation of mummies to museums as the new path to immortality. 
By the late twentieth century, the human body became central to Western culture 'as a site of identity and ... of political struggle' (20: 114). Human remains have subsequently become 'effective symbolic objects' (20:10) through their placements in contexts of scientific study, identity negotiation and power contests between social and political groups (20:119). Modern human remains have become the foci of conflicts such as condemnation of hospitals' retention of juvenile body parts and feminist opposition to paternalistic control of women's lives through reproductive medicine (20: 114-20). Ancient human remains have been used by indigenous and Pagan claimants to fortify their oppressed cultural identities and by museum professionals sympathetic to repatriation claims to redefine and legitimise the role of museums by distancing them from discredited past policies (20:3-6). Controversies about museum exhibition of human remains must therefore be considered as part of a broader developing discourse and subject to its terms. Accordingly, I see connections between the paedophilia panic induced by some exhibitions of nude photography and the terms in which the media has couched opposition to the display of Egyptian mummies.

Media reportage of the Manchester Museum's mummy cover-up interpreted the value of "ethics" as modesty $(19,28)$, whether or not this specific concept was curators' primary motivation in hiding ancient bodies from the modern gaze. This kind of rhetoric is at once a familiar form of contemporary media sensationalism and a strange renaissance of nineteenth century prudery. As Émile Blavet stated in 1887, ' [s]o-called scientific entertainment is very often a simple excuse to show people peculiar things which rather cause scandal ... I rather think that, to many visitors, men and women, these [anatomical] figures are merely there to nurture their dirty fantasies' (6). Concern has been raised about the immodesty of unwrapped mummies ever since unwrapping moved from the private scientific study to the public lecture hall and tabloid press.

Now [Tutankhamun] ... may be stripped, and ... laid half-naked to rot in a glass case ... at Cairo ... thus exposed I doubt whether any [mummies] will last another century; and meanwhile to be made the butt of the merry jests of tourists of the baser sort ... Is this decent? ... Examine them by all means ... but then hide them away again for ever, as we ourselves would be hidden away. Henry Rider Haggard, To the Editor of The Times, 1923 (16)

Insistence that immodest mummies be covered up echoes the interpretation by some people of art as pornography and their demand that it be censored. Parallels between the arguments of those who would cover mummies and those 
who would ban nude photography demonstrate that we are in the grip of a crisis of identity and ethics centred on the body that has been compounded by the sexualisation of the act of looking (3: 111). These parallels also demonstrate that meaning does not inhere in objects or bodies but rather, that it is read into them according to any physical or visual elements they contain that already have meaning in a particular culture. Ideas encoded in symbols are decoded by viewers (17). The problem is that the visible traits of, say, a mummy may remind viewers of some significance that mummies bear outside of the museum context - ideas that curators did not intend to impart. Thus a mummy displayed to illustrate the art of Egyptian embalming can, by virtue of its nudity, also be interpreted to connote sex (more likely by the prudish than by any necrophiles that they fear may be lurking in the museum).

Other visual traits of mummies such as ragged and stained wrappings, exposed bones and soft tissue damage happen to coincide with the symbols used by the media to represent mummies as evil monsters in films, cartoons and toys. In order to overthrow the nineteenth century popular image of mummies as victims and symbols of colonial exploitation, twentieth century cinema elaborated abject motifs around mummies to reassign them to the role of villains. Audiences could thenceforth be co-opted into a fantasy of plundering tombs and destroying the mummies that protected them (11:64-93). This shift in popular representations of mummies created a language of "Egyptian abjection" in terms of which many museum visitors inadvertently read mummies. This application of fictional stereotypes to real mummies occurs because gaps in visitors' factual knowledge about mummies are filled by their existing networks of ideas about ancient Egypt, ideas that tend to derive from media fictions (34: 289). ' $[\mathrm{P}]$ erception and learning hinge upon the accommodation of new information into existing mental structures and frameworks. In museums, people attempt to place what they encounter ... within the context of their experience. Thus, memory may be viewed as the core mechanism of meaning-making' (33:162).

The media and other organisations deliberately precondition exhibition visitors to experience an appropriate emotional response in specific settings; visitors to Holocaust and war museums will feel a responsibility to experience cathartic sadness, pilgrims in churches want to experience elation and tourists in haunted attractions expect to be frightened. Anticipation of a desired emotional experience is what attracts people to such places. However, preconditioning can also occur inadvertently; the media does not represent mummies as monsters in order to frighten children in museums but this is nevertheless the consequence of their discourse. I believe that the preconditioning of museum-goers to fear 
and be repulsed by mummies accounts for a significant proportion, possibly a majority, of objections to their display.

Q: How do you feel about Egyptian mummies being displayed in museums?

A: It's fine as long as they're not out in the open.

Q: What would happen if they were out in the open?

A: Rot, smell. It's gross ... sickness and that.

Male, 13 years, Field Museum interviews, 1996 (11: 108)

If meaning is not inherent - if people who think that mummies or nudes are pornographic or repulsive are reading too much into the exhibit - then it follows that there is nothing inherently disrespectful about displaying Egyptian mummies. Wijnand van der Sanden wants to stop the use of graphic images of European bog bodies on commercial products but does not extend this proposed ban to the display of the mummies themselves (36); while images of the bodies are encoded so as to encourage viewers to interpret them in ways that are arguably disrespectful, the bodies themselves have no inherent meanings. It is only the custom of associating human remains with sacredness and knowledge that makes them the fulcrum of disputes about cultural identity and values (20: 107-8). While Egyptian mummies were once widely used to articulate conflicts of ethnicity, gender, politics and religion within Western societies, they did not cause or come to embody any postcolonial conflict between Europe and Egypt. Some iconic antiquities held by museums abroad have been subject to Egyptian repatriation requests, but not mummies. Thus mummies could continue to be displayed without raising any significant issues, at least for the time being.

\section{A SOLUTION}

[F]or there is nothing either good or bad, but thinking makes it so.

William Shakespeare, Hamlet II. ii. 1350-1, ca1599-1601 (32)

What would a perfect Egyptian mummy display be like? Let us begin with the idea that respect for mummies might be expressed more effectively through displaying them than through removing them from display. Reactions to similar types of human remains can vary according to their context of display or the discourses articulated through them (20: 120), in which case it should be possible to devise better ways of presenting mummies that win the approval of visitors. It should be remembered that many visitors experience awe and wonder when looking at mummies and that for many Egyptophiles, visiting them is akin to 
a Catholic's visit to a church to venerate the mummy of a saint. This notion of paying a visit to a person and not just to a museum per se is a key element of the humanisation of mummies through public exhibition.

What the visitor should be visiting is a virtual tomb. A common scenario in cinema, cartoons and comics since the mid-twentieth century has been a mummy coming to life in a museum, responding to disturbance of its new resting place by marauders as it would have responded to disturbance of its tomb. In other words, popular culture tacitly recognises museum displays of mummies as virtual tombs and in the image of a mummy smashing glass cases, condemns the "cold scientific" classification of mummies as mere specimens (11: 78-81). Although Egyptian tombs featured plain or decorated stone walls and some old and new museum exhibits display their mummies in recreations of these settings, it is the darkness of subterranean spaces that connotes a tomb to many museum visitors in my experience. Even exhibition spaces with black walls and low lighting that do not set out to represent tombs may be interpreted in this way by visitors (11:144). There is also an audial dimension to a tomblike atmosphere, namely a reverent silence; visitors to the Royal Mummies Room at the Cairo Museum are asked to remain quiet, although in practice this can be difficult to achieve. The popularity of mummy exhibits with children necessarily makes them noisy places at times. It is possible that including several seats in mummy displays could encourage quiet reflection and a longer visit; consider that many Victorian mausolea included seats and that bereaved people can purchase wooden benches commemorating their departed friends and family members in Kew Gardens. Seats in art galleries frequently encourage visitors not only to relieve their tired feet but also to contemplate their surroundings.

To what extent should mummy displays attempt to determine how visitors interpret what they see? The fact that many visitors make negative interpretations of mummies as a consequence of the influence of media stereotypes demonstrates that the museum paradigm of the 1990s - that visitors should have complete freedom to interpret exhibits $(1: 105 ; 9: 217-8 ; 33: 165,167)$ - is flawed. Curators' voices arguably have a right to be heard in order that as many visitors as possible should be dissuaded from making negative interpretations prejudicial to the positive intent of the display. 'We cannot stop visitors coming to their own interpretations, but ... we should be concerned to communicate our preferred readings through the power, clarity and relevance of our work' (24:10-1). '[E]xhibition should be defined as 'showing for a purpose', the purpose being to affect the viewer in some predetermined way' (5:37). When exhibiting a nude photograph of a juvenile Brooke Shields in 2009, the Tate 
Modern gallery countered potential allegations of encouraging paedophilia by prefacing its display with a warning about its content and an explanation of the photographer's intent as an artist, although the photograph was finally removed after protests from child protection groups (29). The Tate case is controversial, but demonstrates a current trend in favour of the restoration of curators' right to be heard and to contest some public interpretations of their exhibits. It would not therefore be outrageous for a curator to explain and defend the exhibition of a mummy, although given the problematic sexualisation of the act of looking, it would seem wise to cover at least the genital areas and female breasts of completely unwrapped mummies. An experimental method of display that gives visitors the choice of whether or not to look at an exhibit has been attempted in several Egyptology exhibitions, including the 2001 British Digging for Dreams touring exhibition in which visitors could choose whether to reveal mummy fragments covered by a shroud (22) and the Manchester Museum's addition of warning labels at the entrances to its mummy gallery. Such measures are in my view a reasonable way to negotiate the expectations of both visitors who want to see mummies and those who dislike looking at them or even being in the presence of human remains.

How should mummies be labelled? Firstly, mummy and ancient Egypt exhibits should be prefaced or at least interspersed with panels inviting visitors to make critical comparisons and distinctions between common myths and historical realities about mummies. Secondly, Tiffany Jenkins has noted the recent development of an explicitly humanising paradigm of human remains display exemplified by the Wellcome Collection's 2008 exhibition Skeletons: London's Buried Bones. Label content described each body as an individual rather than a specimen and presented science as the key to unlocking his or her identity and life history (20: 138). How much greater an advantage do curators of Egyptian mummies have, since so many have known names, family members and professions? Even before most curators could read hieroglyphic inscriptions on coffins, writers and poets tried to imagine the past lives of mummies (13), so curators are, in fact, following a tradition in which Egyptian mummies have been routinely humanised, notwithstanding the coexistence of this idea with images of mummies as monsters. The public is familiar with the concept of mummies as sentient beings and museums should capitalise upon this. The Egyptian exhibit at the New Walk Museum in Leicester opens with a wrapped mummy's head, a disembodied thing that could easily be treated as an object, but through a label, the mummy speaks. She asks visitors to reflect upon what they already know about ancient Egypt and to consider the circumstances in 
which she came to Leicester. She then invites them into the exhibition to learn more about her people. The exhibit designers have been accused of putting words in the mummy's mouth $(18: 13,15)$, but as the writers of nineteenth century "talking mummy" poems found, such a contrivance is necessary to humanise the mummy (13) - a consideration which, in light of the dehumanisation of mummies in horror films, overrides pedantic concerns about power.

Several museums now ask visitors to say a prayer for their mummies, including the Field Museum via a large text panel and the Manchester Museum via one curator's verbal request (20:129). Such measures are arguably salves for curators' consciences (20: 129), but then again, any measures taken by any culture to honour the dead serve to assuage the guilt of the living and to re-establish their values in the face of the social chaos wrought by death (7). Through prayers, some curators have effectively improvised memorial services for mummies. There is a growing need to understand human remains in a personal, spiritual way - even to address a sense of regret for past disturbance and theft of mummies - and saying prayers for them neatly fills this need. It would make no more sense in my view to censor such expressions of sensitivity than to ban annual memorial services for those who lost their lives in war. What concerns me is that while such memorial services do not supplant historical research and debate about the causes and consequences of war, there is a real danger that too much talk of mummies' display being unethical is causing museums to take mummies off display, ironically shutting down public access to the very remains to which many people wish to pay respect.

My favourite mummy exhibit is that of the mummy claimed to be Rameses I, voluntarily repatriated to Egypt by the Michael C. Carlos Museum in Atlanta, Georgia following its acquisition from the defunct Niagara Falls Museum and subsequently installed in the Luxor Museum. This is an art museum, but its "dark room with pin lights" look creates an atmosphere of repose and dignity perfectly suited to mummy exhibition. Displayed on his own in a dark, tomblike room accessible through a single doorway, the mummy can be seen by those who choose to visit him. He cannot be photographed. He is surrounded by only several objects in wall vitrines and labelling inside the room is kept to a minimum. Much of the room consists of empty space. This could accommodate a crowd but at other times it generates an atmosphere of repose and silence. One approaches the room via several stairs; the mummy is elevated above the other exhibits, set apart as a special entity. Within this place there is time and space to feel, think and reflect. I spent ten minutes with Rameses, if that is indeed his name, talking to him in my mind and smiling. I want other people to have the chance to feel this way about him too, and others like him. 


\section{CONCLUSION}

While the inclusion of Egyptian mummies in explicit ethical debates about the management of human remains is a recent development, disputes about their treatment are nothing new. The legend of the "mummy's curse", which was spawned by nineteenth century horror fiction but later distorted and abstracted by the mass media, originated as an objection to the contemporary destruction and degrading commodification of mummies. It was the precursor to today's human remains debates, couched in popular mythological terms at a time when explicit opposition to institutional scientific practice and sympathy with the victims of colonial despoliation was socially unacceptable (11). Despite this history of controversy, the exhibition of Egyptian mummies continued - tolerated, perhaps, as the colonial system that produced it faded away - until museums became the only places in which most people could see them. Now even that slim thread of connection may be cut.

The Egyptian mummy display debate is not really about museums, but about Western public values: the failure of our culture to educate people to look at bodies, living or dead, and see anything other than pornography or horror. People need to learn to see art, not porn and to envision the lives of the dead. Why do parents and schools fail to teach people how to look with respect, how to invest bodies and representations of bodies with positive meaning? Why are the media allowed to implant disrespect for the human body in the human mind and why do we accept their way of looking? Instead of asking how to fix museums, we must ask: how do we fix schools, parenting and, in particular, the media? The human remains debate reflects a broader malaise in Western society - its modern history that is fraught with body politics and an overreaction against the legacy of Victorian sexual guilt.

Why overturn the way museums work when all that is needed is a change of attitude? The problem is not that Egyptian mummies are on public display. The problem is that members of the public often bring the wrong mindset to viewing them, which curators - convinced that mummies should not be treated differently to other, more contentious remains - may misinterpret as an additional reason to take mummies off display. The solution is a combination of public education about death, the body and cultural difference and a rethinking of issues by curators to produce displays that effectively cultivate in visitors a sense of respect for ancient Egyptians. There is no need to patronise the public by revoking people's right to seek meaning through encounters with human remains - encounters that were once freely available, before undertakers, doctors and curators sequestered the dead. 


\section{REFERENCES}

1. Ames M. (1992). Cannibal Tours and Glass Boxes: the anthropology of museums. University of British Columbia Press. Vancouver.

2. Anonymous (ca1847-54). Signor Sarti's Celebrated Florentine Anatomical Venus: together with numerous smaller models of special interest to ladies, showing the marvellous mechanism of the human body. Philosophical Hall. Huddersfield.

3. Bartlett A. (2008). Sex sells: child sexualisation and the media. Screen Education, 51, 106-12.

4. Bates A.W. (2008). "Indecent and demoralising representations": public anatomy museums in mid-Victorian England. Medical History, 52, 1, 1-22.

5. Belcher M. (1991). Exhibitions in Museums. Leicester University Press. Leicester \& London.

6. Blavet É. (1887). La Vie Parisienne. Paris. Paul Ollendorff.

7. Bloch M., Parry J. (1982). Introduction. In: Bloch M., Parry J. (eds), Death and the Regeneration of Life. Cambridge University Press. Cambridge, New York. $1-44$.

8. Brier B. (1998). The Encyclopedia of Mummies. Facts on File. New York.

9. Clifford J. (1997). Routes: Travel and Translation in the Late Twentieth Century. Harvard University Press. Cambridge, Massachusetts \& London.

10. Daly N. (1994). That obscure object of desire: Victorian commodity culture and fictions of the mummy. Novel: a forum on fiction, 28, 1, 24-51.

11. Day J. (2006). The Mummy's Curse: mummymania in the English-speaking world. Routledge. London \& New York.

12. Day J. (2008). The rape of the mummy: women, horror fiction and the Westernisation of the curse. In: Peña P.A., Martín C. R., Rodríguez M.A.R. (eds), Mummies and Science - world mummies research: proceedings of the VI World Congress on Mummy Studies. Academia Canaria de la Historia. Santa Cruz de Tenerife. 617-21.

13. Day J. (2013). The maid and the mummy. In: Dann R., Exell K. (eds), Egypt: ancient histories, modern archaeologies. Cambria Press Inc. New York. 193-232.

14. English Heritage (2009). Research into Issues Surrounding Human Bones in Museums. BDRC. London.

15. Frayling C. (1992). The Face of Tutankhamun. Faber \& Faber. London \& Boston.

16. Haggard H. R. (1923). King Tutankhamen. Reburial in Great Pyramid. Sir Rider Haggard's plea. To the Editor of The Times. The Times (London), 13 February, p.13. 
17. Hall S. (1980). Encoding/decoding. In: Hall S., Hobson D., Lowe A., Willis P. (eds), Culture, Media, Language: working papers in cultural studies, 1972-79. Hutchinson in association with the Centre for Contemporary Cultural Studies, University of Birmingham. London. 128-38.

18. Innes K. (1997). Death and the museum: the museum as memento mori. Museological Review, 4, 12-28.

19. Inquirer.net (2008). Egypt antiquities chief hails 'naked' mummies cover-up. 22 May.

20. Jenkins T. (2011). Contesting Human Remains in Museum Collections: the crisis of cultural authority. Routledge. London \& New York.

21. Kilmister H. (2003). Visitor perceptions of ancient Egyptian human remains in three United Kingdom museums. Papers from the Institute of Archaeology, $14,57-69$.

22. MacDonald S. (2001). An experiment in access. Paper presented at ICOM International Conference, Barcelona, 4 July.

23. Michell N. (1860). The mummy of Thebes. The New Monthly Magazine, 120, 188-90.

24. Miles R. (1997). No royal road to learning: a commentary on constructivism. Visitor Behaviour, 12, 3, 7-13.

25. Manchester University Museum (2008a). Egyptian Mummies: we're listening to your views. Press release. Manchester University Museum. Manchester.

26. Manchester University Museum (2008b). Covering the mummies. Available at: Egypt at the Manchester Museum.

27. Manchester University Museum (2008c). Official Statement on Covering Egyptian Mummies. Manchester University Museum. Manchester.

28. Narain J. (2008). Fury as museum bosses cover up naked Egyptian mummies to protect 'sensitivities' of visitors. Mail Online, 21 May.

29. Revoir P. (2009). Tate removes nude picture of 10-year-old Brooke Shields after police pornography probe. Mail Online, 1 October.

30. Rühli F.J., Kaufmann I.M. (2010). Without 'informed consent'? Ethics and ancient mummy research. Journal of Medical Ethics, 36, 608-13.

31. Parkinson R. (trans.) (1991). Voices from Ancient Egypt: an Anthology of Middle Kingdom Writings. The British Museum Press. London.

32. Shakespeare W. (ca1599-1601). The Tragedy of Hamlet, Prince of Denmark (a.k.a. Hamlet). Available at: OpenSource Shakespeare.

33. Silverman L. (1995). Visitor meaning-making in museums for a new age. Curator, 38, 161-70.

34. Strauss C., Quinn N. (1994). A cognitive/cultural anthropology. In: Borofsky R. (ed.), Assessing Cultural Anthropology. McGraw-Hill Inc. New York. 284-97. 
35. Swaney M. (2013). The Living Dead: Egyptian mummies and the ethics of display. MA thesis. Program in Museum Studies, Graduate School of Arts and Science, New York University. New York.

36. van der Sanden W. (2005). Mummies, mugs, and museum shops. Archaeology, August 30. Available at: Archaeology.org.

\section{Address for correspondence:}

Dr Jasmine Day

22 Coolidge Street

Como, Western Australia 6152

Perth

Australia 